\title{
JNJ-26481585 primes rhabdomyosarcoma cells for chemotherapeutics by engaging the mitochondrial pathway of apoptosis
}

\author{
Ulrike Heinicke $^{1}$, Johanna Kupka ${ }^{1}$ and Simone Fulda ${ }^{1,2,3}$ \\ ${ }^{1}$ Institute for Experimental Cancer Research in Pediatrics, Goethe-University, Frankfurt, Germany \\ 2 German Cancer Consortium (DKTK), Heidelberg, Germany \\ ${ }^{3}$ German Cancer Research Center (DKFZ), Heidelberg, Germany \\ Correspondence to: Simone Fulda, email: simone.fulda@kgu.de \\ Keywords: apoptosis, cell death, rhabdomyosarcoma, HDACl, mitochondria \\ Received: May 31,2015 Accepted: September 26, $2015 \quad$ Published: October 12, 2015
}

This is an open-access article distributed under the terms of the Creative Commons Attribution License, which permits unrestricted use, distribution, and reproduction in any medium, provided the original author and source are credited.

\section{ABSTRACT}

Rhabdomyosarcoma (RMS) is a common soft-tissue sarcoma in childhood with a poor prognosis, highlighting the need for new treatment strategies. Here we identify a synergistic interaction of the second-generation histone deacetylase inhibitor (HDACI) JNJ-26481585 and common chemotherapeutic drugs (i.e. Doxorubicin, Etoposide, Vincristine, Cyclophosphamide and Actinomycin D) to trigger apoptosis in RMS cells. Importantly, JNJ-26481585/Doxorubicin cotreatment also significantly suppresses long-term clonogenic survival of RMS cells and tumor growth in vivo in a preclinical RMS model. Mechanistically, JNJ-26481585/Doxorubicin cotreatment causes upregulation of the BH3-only proteins Bim and Noxa as well as downregulation of the antiapoptotic proteins $\mathrm{Mcl}-1$ and $\mathrm{Bcl}-\mathrm{x}_{\mathrm{L}}$. These changes in the ratio of proand antiapoptotic Bcl-2 proteins contribute to JNJ-26481585/Doxorubicin-mediated apoptosis, since knockdown of Bim or Noxa significantly inhibits cell death. Also, JNJ26481585 and Doxorubicin cooperate to stimulate activation of Bax and Bak, which is required for JNJ-26481585/Doxorubicin-induced apoptosis, since silencing of Bax or Bak protects against apoptosis. Consistently, overexpression of $\mathrm{Bcl}-2$ significantly reduces JNJ-26481585/Doxorubicin-mediated apoptosis. JNJ-26481585/Doxorubicin cotreatment leads to caspase activation and caspase-dependent apoptosis, since the broad-range caspase inhibitor $\mathrm{N}$-benzyloxycarbonyl-Val-Ala-Asp-fluoromethylketone (zVAD.fmk) rescues cells from apoptosis. In conclusion, the second-generation HDACI JNJ-26481585 cooperates with chemotherapeutics to engage mitochondrial apoptosis in RMS cells, demonstrating that JNJ-26481585 represents a promising strategy for chemosensitization of RMS.

\section{INTRODUCTION}

RMS is one of the most common soft-tissue sarcomas in children, which comprises two major subtypes, i.e. alveolar rhabdomyosarcoma (ARMS) and embryonal rhabdomyosarcoma (ERMS) [1, 2]. Despite multimodal treatment regimens and advances in combination chemotherapy, patients with primary metastatic disease or relapse are largely resistant to current treatment protocols and have a dismal chance for cure of less than $20 \%$ [3]. This highlights the high medical need to develop new treatment regimens in RMS to improve the poor prognosis of these patients. Since conventional therapies with common chemotherapeutics have already been optimized in recent years, new experimental therapies seem to be necessary to improve the outcome of RMS patients, especially with high-risk disease.

Histone deacetylases (HDACs) determine the acetylation status of histones, thereby affecting chromatin topology and gene expression [4]. In addition to histones, HDACs are also able to interact and deacetylate nonhistone proteins, thereby affecting their activity, 
localization or interaction with other proteins [4]. Since HDACs have been shown to be upregulated in many cancer entities, they are considered to represent potential targets for treatment strategies $[5,6]$. As a relatively new class of anticancer agents, HDACIs have been shown to induce apoptosis in a variety of cancer cells [7].

HDACIs are able to engage cell death mainly via the two well-described apoptotic pathways, i.e. the extrinsic (death receptor) pathway and the intrinsic (mitochondrial) pathway, which both result in the activation of caspases [8]. Mitochondrial outer membrane permeabilization (MOMP) constitutes a central event in the mitochondrial pathway of apoptosis and is tightly controlled by several pro- and antiapoptotic proteins of the Bcl-2 family [9]. This includes on the one side antiapoptotic proteins (e.g. Bcl-2, Bcl- $x_{L}$ and $\mathrm{Mcl}-1$ ) and on the other side proapoptotic members such as $\mathrm{BH} 3$-only proteins (e.g. Bim, Noxa and Bmf) and the multidomain proteins Bax and Bak [10]. MOMP involves activation of Bax and Bak as pore-forming proteins in the mitochondrial membranes, which results in the release of proteins from the mitochondrial intermembrane space including cytochrome c. In the cytosol, cytochrome c promotes the formation of the apoptosome leading to activation of caspases and apoptotic cell death [9].

JNJ-26481585 (Quisinostat) is a new secondgeneration, pyrimidyl-hydroxamic acid HDACI, which has a high potency towards class I and II HDACs [11]. JNJ-26481585 showed antitumor activity in patients with advanced solid tumors [11, 12] and in mouse models of multiple myeloma with almost complete reduction of tumor burden [13]. JNJ-26481585 has been documented by the Pediatric Preclinical Testing Program to exhibit improved efficiency compared to common HDACIs, e.g. SAHA (Vorinostat), underscoring that it represents a promising new agent for the treatment of childhood cancers including RMS [14]. Since chemotherapy is a central pillar of current treatment protocols for RMS, anticancer drugs are prime candidates for rational combinations with JNJ-26481585. However, so far it is not known whether or not JNJ-26481585 can be used to increase chemosensitivity of RMS cells. Therefore, the current study aims at investigating the question whether JNJ-26481585 sensitizes RMS cells for chemotherapyinduced cell death and at understanding the underlying molecular mechanisms of action.

\section{RESULTS}

\section{JNJ-26481585 synergizes with clinically used chemotherapeutic drugs to induce apoptosis in RMS cells}

To address the question whether JNJ-26481585 can increase chemosensitivity of RMS cells, we tested the effects of JNJ-26481585 alone and together with chemotherapeutic drugs that are commonly used in clinical trial protocols for the treatment of RMS [15]. We assessed apoptosis by analysis of DNA fragmentation as a characteristic marker of apoptotic cell death in RMS cell lines comprising both the ERMS (RD, TE381.T) and ARMS (Rh30, RMS13) subtypes. Importantly, suboptimal concentrations of JNJ-26481585 synergized with various anticancer drugs, including the topoisomerase II inhibitors Doxorubicin and Etoposide, the vinca alkaloid Vincristine, the alkylating agent Cyclophosphamide and the cytotoxic antibiotic Actinomycin D, to trigger apoptosis in RMS cells as confirmed by calculation of (CI), while treatment with JNJ-26481585 alone induced apoptosis in a dosedependent manner (Figure 1A-1E, suppl. Figure 1). Concomitant analysis of the acetylation status of histone H3 confirmed that JNJ-26481585 increased histone H3 acetylation under these conditions (Figure 1F). Compared to RMS cells, we observed no additive cytotoxicity of JNJ-26481585 together with Doxorubicin or Etoposide against fibroblasts (Suppl. Figure 2), pointing to some tumor selectivity.

We additionally analyzed SYTOX ${ }^{\circledR}$ Blue-stained nuclei in Rh30 cells as another marker of cell death. Combined treatment or Rh30 cells with JNJ-26481585 and Doxorubicin significantly increased the percentage of SYTOX ${ }^{\circledR}$ Blue-positive cells (Suppl. Figure 3A). Pharmacological rescue experiments showed that addition of the broad-range caspase inhibitor zVAD.fmk, but not the receptor-interacting protein kinase 1 (RIPK1) inhibitor Necrostatin-1s significantly inhibited JNJ-26481585/ Doxorubicin-induced cell death (Suppl. Figure 3B), underscoring that JNJ-26481585/Doxorubicin cotreatment triggers apoptotic cell death. This set of experiments demonstrates that JNJ-26481585 sensitizes RMS cells for several clinically used chemotherapeutic agents.

\section{JNJ-26481585/Doxorubicin cotreatment suppresses clonogenicity of RMS cells and reduces tumor growth in vivo}

After this initial screening for synergistic drug interactions, we focused our subsequent studies on JNJ-26481585/Doxorubicin cotreatment, since this combination turned out to be very potent and since 
A
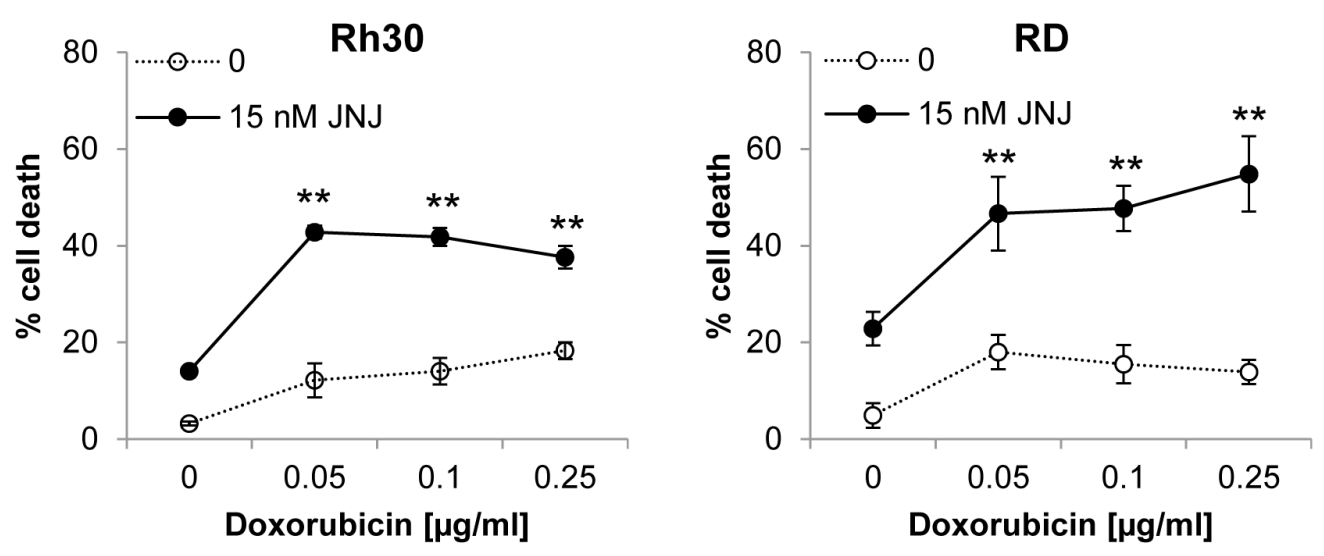

B
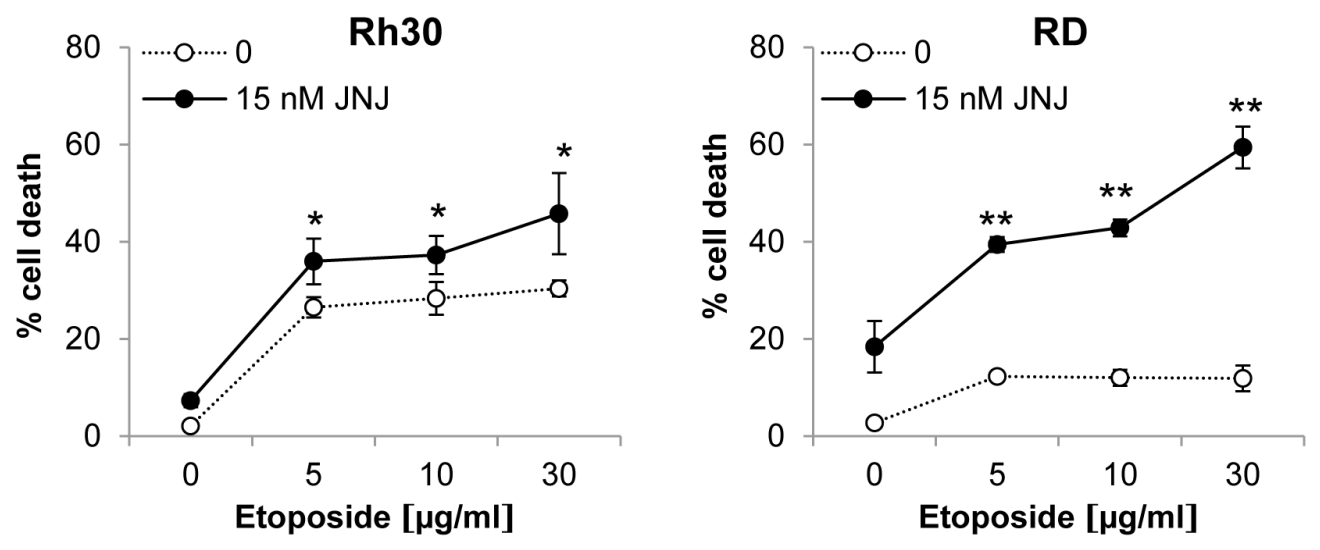

C
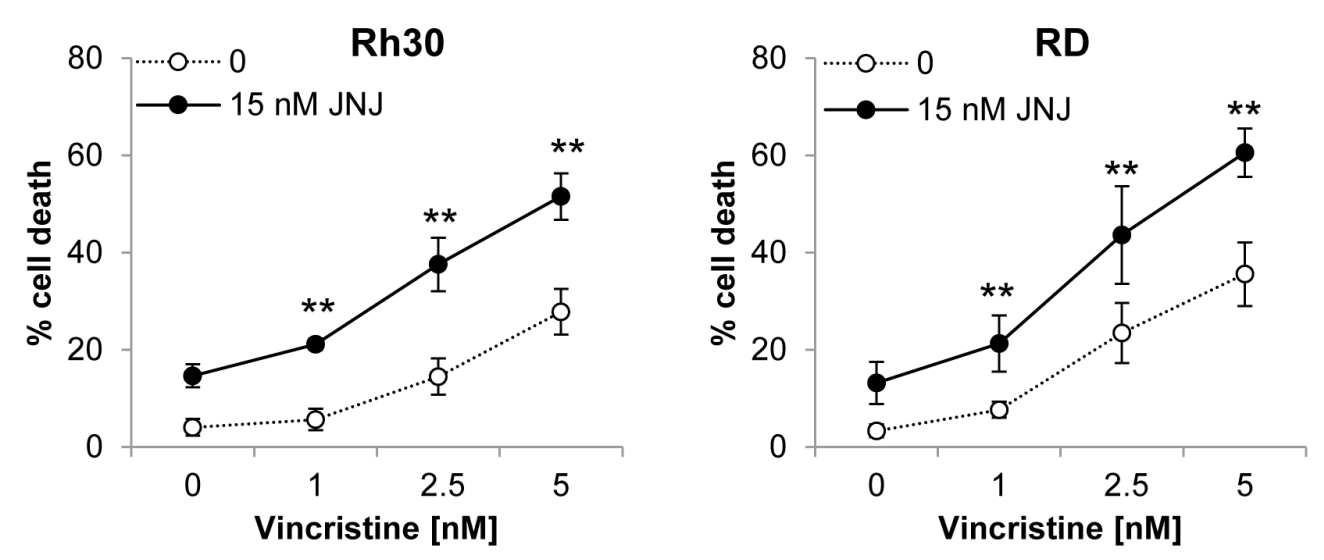

D

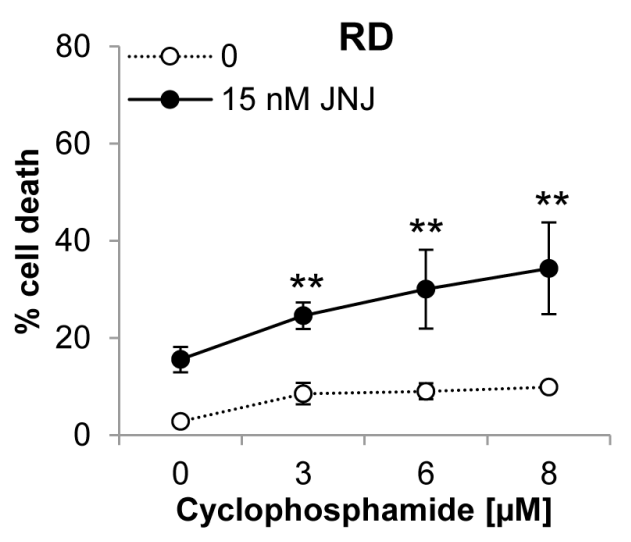


$\mathbf{E}$
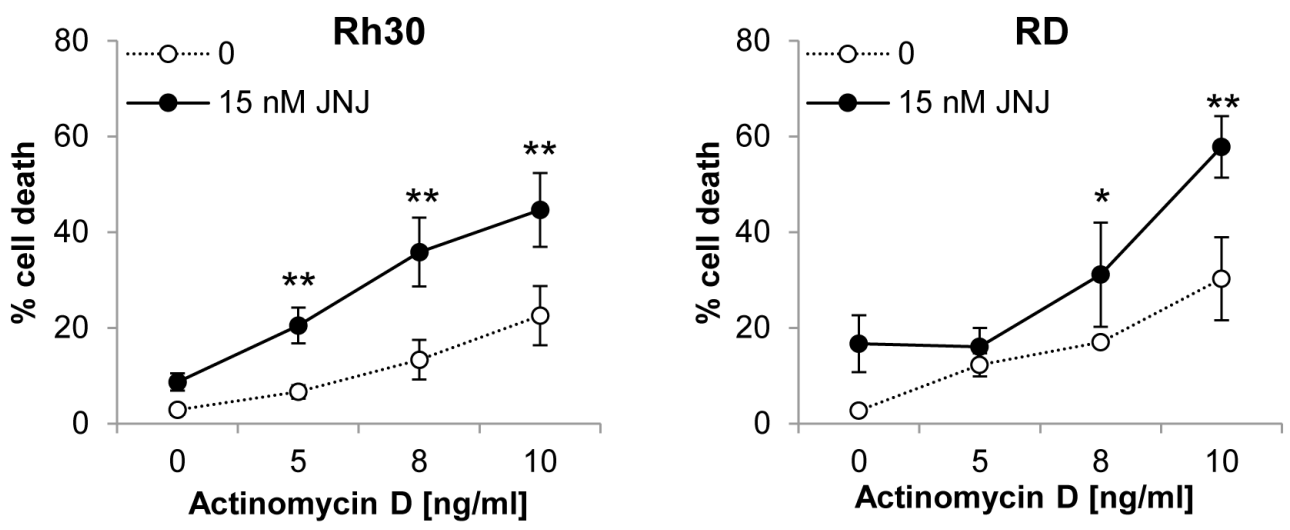

$\mathbf{F}$

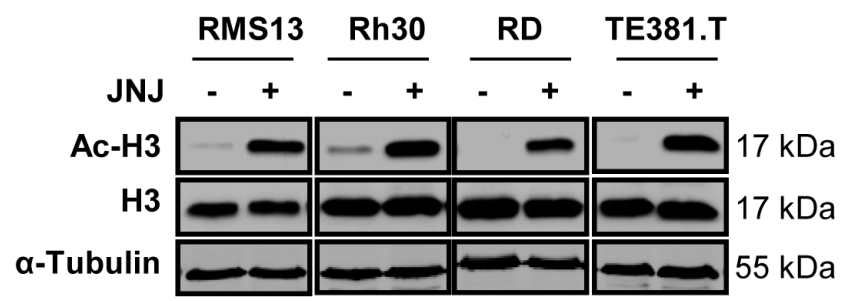

Figure 1: JNJ-26481585 synergizes with clinically used chemotherapeutic drugs to induce apoptosis in RMS cells. A.-E., Cells were treated with 15 nM JNJ-26481585 and/or indicated concentrations of Doxorubicin A., Etoposide B., Vincristine C., Cyclophosphamide D. or Actinomycin D E. for 48 hours A.-D. or 72 hours E. Apoptosis was determined by analysis of DNA fragmentation of PI-stained nuclei using flow cytometry. Mean and SD of three experiments performed in triplicate are shown; ${ }^{*} P<0.05$, $* * P<0.01$. F., Cells were treated with $15 \mathrm{nM} \mathrm{JNJ}-26481585$ for 6 hours. Protein expression of acetylated histone H3 (Ac-H3), H3 and $\alpha$-Tubulin was assessed by Western blotting.

Doxorubicin is often clinically used. To explore whether the cotreatment with JNJ-26481585/Doxorubicin has an influence on long-term clonogenic survival of RMS cells, we performed colony assays. Notably, the combination of JNJ-26481585 and Doxorubicin significantly reduced colony formation of RMS cells compared to treatment with either agent alone (Figure 2A).

To assess the antitumor activity of JNJ-26481585/ Doxorubicin cotreatment against RMS in vivo, we used the chorioallantoic membrane (CAM) model that has successfully been employed in the past to test the anticancer effects of experimental compounds [16-18] and that proved to represent a suitable preclinical RMS model yielding comparable results to xenograft mouse studies [19]. In this model, we implanted RMS cells onto the CAM of chicken embryos, allowed the cells to form tumors and treated them with JNJ-26481585 and Doxorubicin on three consecutive days. On day four, tumors together with the surrounding CAM were sampled for assessment of tumor growth. Importantly, cotreatment with JNJ-26481585/ Doxorubicin significantly reduced tumor growth (Figure 2B). Together, these findings show that JNJ-26481585/
Doxorubicin cotreatment suppresses clonogenic survival and tumor growth in vivo in preclinical RMS models.

\section{JNJ-26481585 and Doxorubicin cooperate to induce caspase activation and caspase-dependent apoptosis}

To gain insights into the underlying molecular events of the observed JNJ-26481585-mediated chemosensitization, we monitored activation of caspases known as key mediators of apoptosis. To this end, we analyzed cleavage of caspases into their active fragments by Western blotting. Notably, JNJ-26481585 and Doxorubicin acted together to trigger cleavage of caspase- 8 into active p43/p41 fragments, cleavage of caspase- 9 into active p37/p35 fragments, cleavage of caspase-3 into active $\mathrm{p} 17 / \mathrm{p} 12$ fragments and cleavage of poly ADP ribose polymerase 1 (PARP) into p89 fragment (Figure 3A). A kinetic analysis revealed that this concerted action of JNJ25481585 and Doxorubicin to trigger caspase activation occurred at the onset of apoptosis and that the rate of apoptosis upon JNJ-26481585/Doxorubicin cotreatment 
A

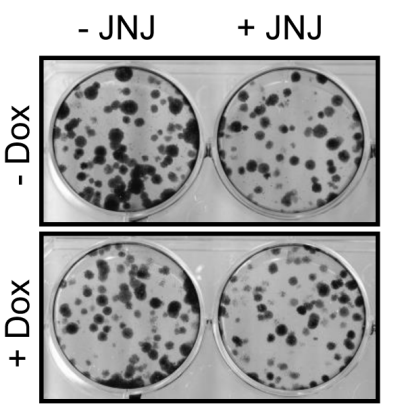

Rh30

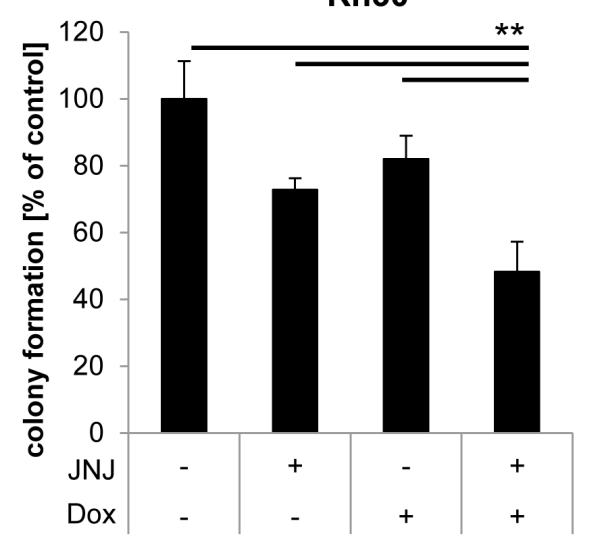

RD
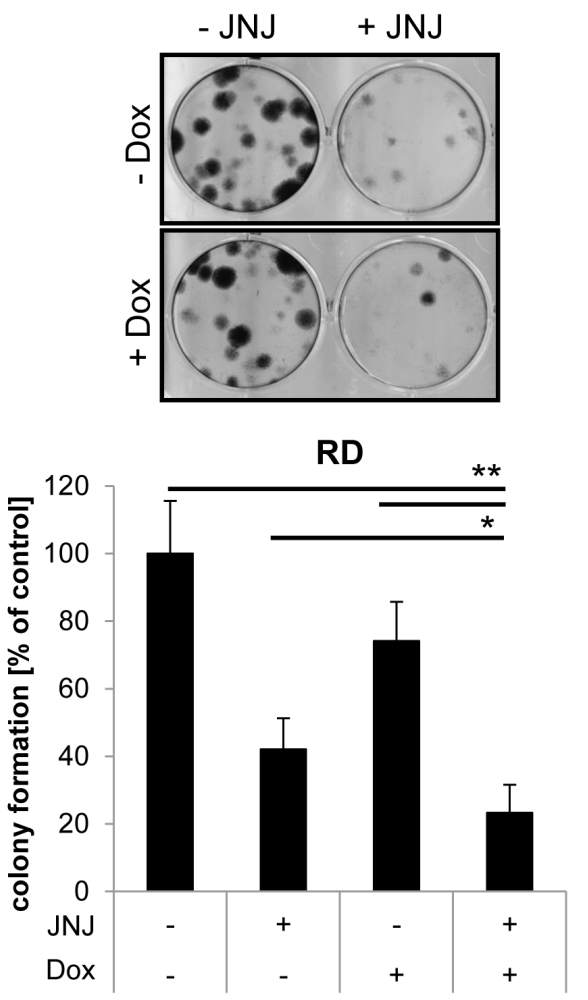

B

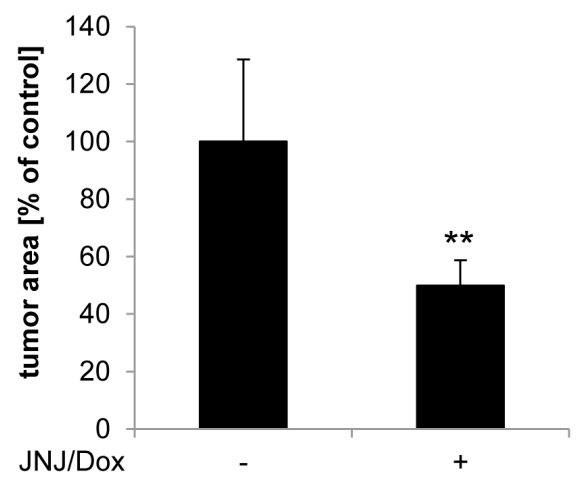

DMSO

$\mathrm{JNJ} / \mathrm{Dox}$
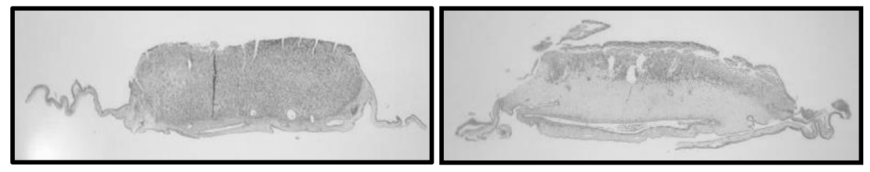

Figure 2: JNJ-26481585/Doxorubicin cotreatment suppresses clonogenicity of RMS cells and reduces tumor growth in vivo. A., Cells were treated with $7.5 \mathrm{nM}$ of JNJ-26481585 for 23 hours before $0.015 \mu \mathrm{g} / \mathrm{ml}$ Doxorubicin was added for 1 hour. Colony formation was assessed after 12 days as described in Material and Methods. The number of colonies is expressed as percentage of solvent-treated controls (lower panels) and representative images are shown (upper panels). Mean and SEM of at least three independent experiments carried out in duplicate are shown. B., RD cells were seeded on the CAM of fertilized chicken eggs, treated with $15 \mathrm{nM} \mathrm{JNJ-}$ 26481585 and $0.25 \mu \mathrm{g} / \mathrm{ml}$ Doxorubicin for three days and tumor growth was analyzed using hematoxylin and eosin (H/E)-stained paraffin sections of the CAM. Representative pictures and quantification of tumor area of at least 17 tumors are shown. Mean and SEM of three independent experiments are shown; $* * P<0.01$. 
increased in a time-dependent manner (Figure 3B). To test whether caspase activation is required for apoptosis, we compared the ability of JNJ-26481585/Doxorubicin cotreatment to induce apoptosis in the presence and absence of the broad-range caspase inhibitor zVAD. fmk. Importantly, the addition of zVAD.fmk significantly reduced JNJ-26481585/Doxorubicin-mediated apoptosis as assessed by the analysis of DNA fragmentation (Figure 3C). Similarly, this protective effect of zVAD.fmk against
JNJ-26481585/Doxorubicin cotreatment was observed when cell viability was determined by two distinct assays, i.e. 3-(4,5-dimethylthiazol-2-yl)-2,5-diphenyltetrazolium bromide (MTT) assay and crystal violet assay, since zVAD.fmk significantly rescued cells from JNJ-26481585/ Doxorubicin-imposed loss of cell viability (Figure 3D, $3 \mathrm{E})$. Together, these experiments demonstrate that JNJ26481585 and Doxorubicin act in concert to induce caspase activation and caspase-dependent apoptosis.

\section{A}

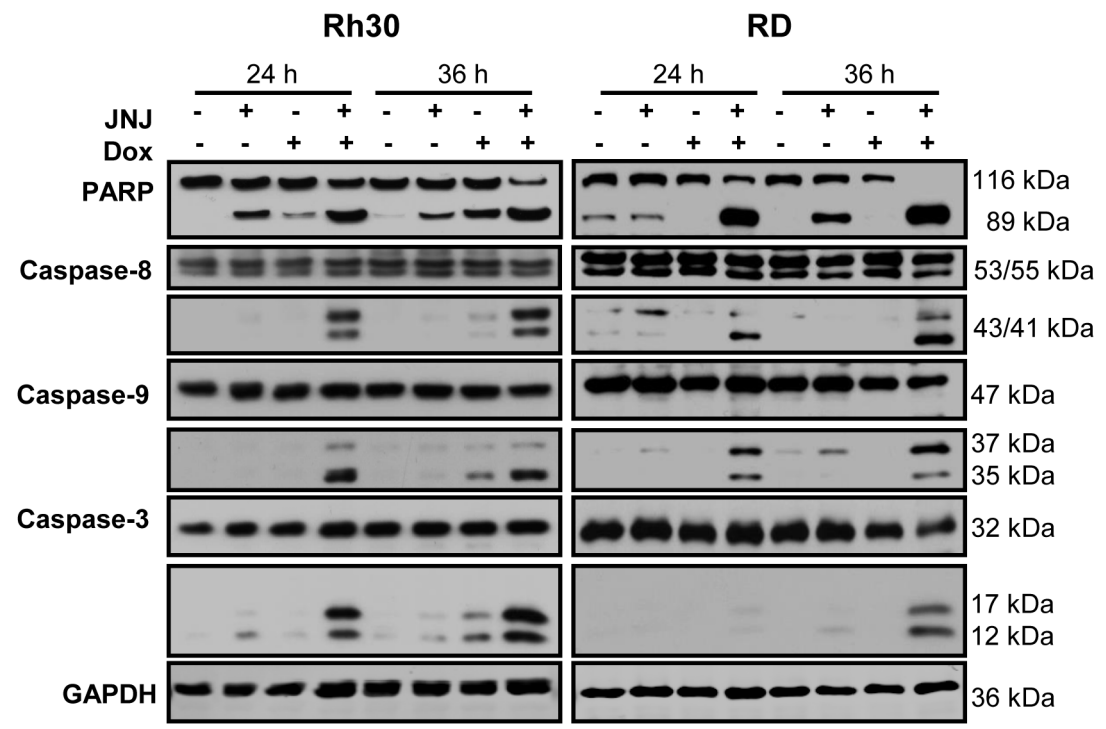

B
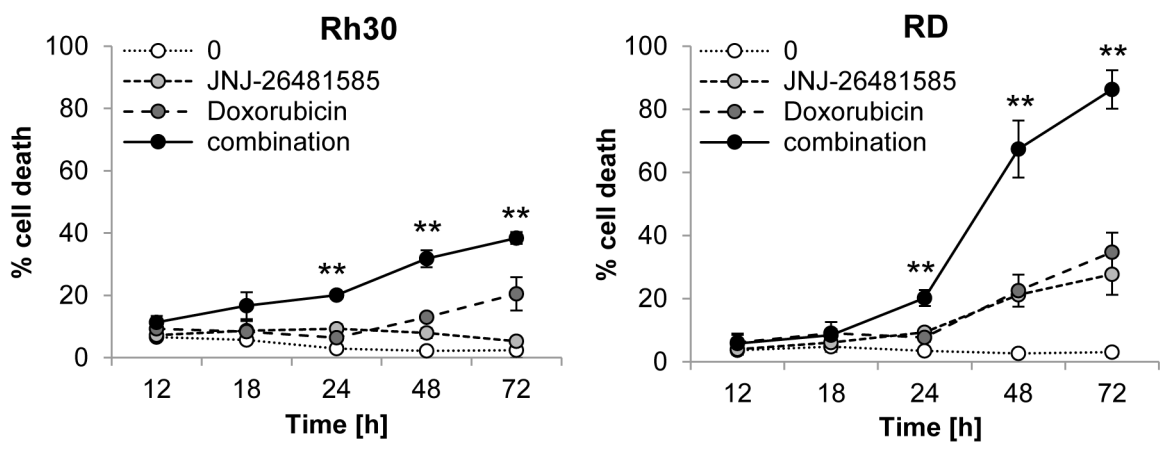

C
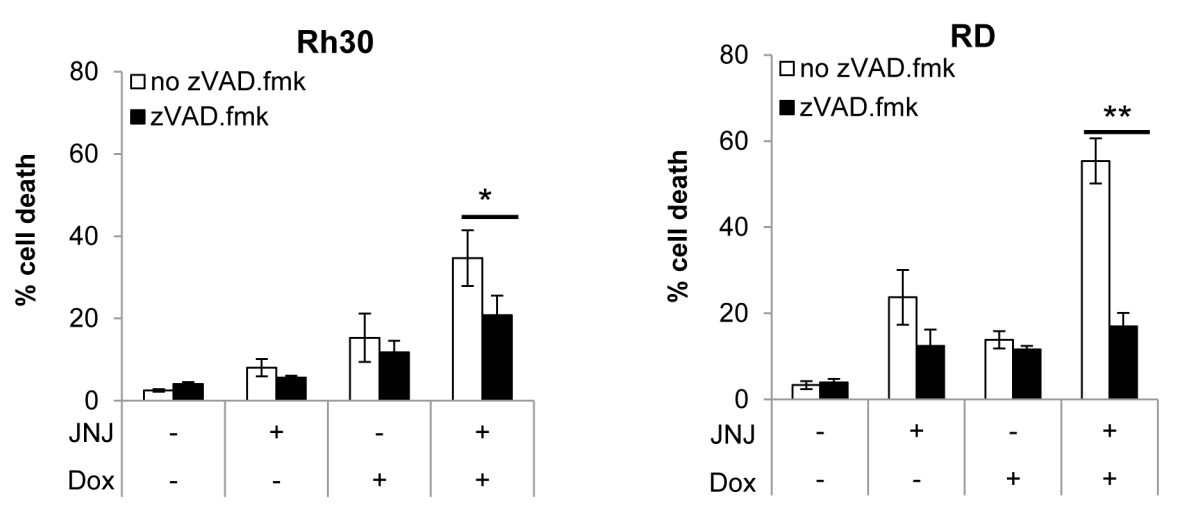
D

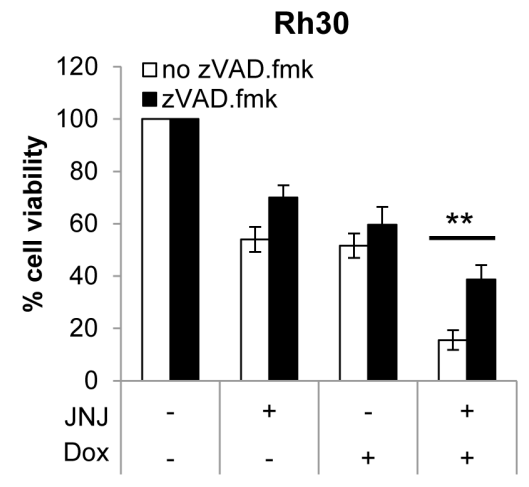

E

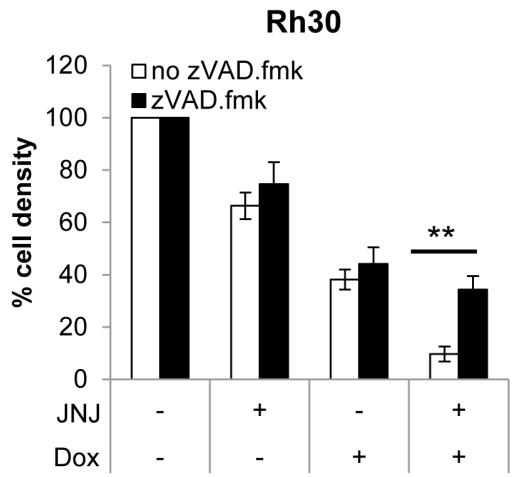

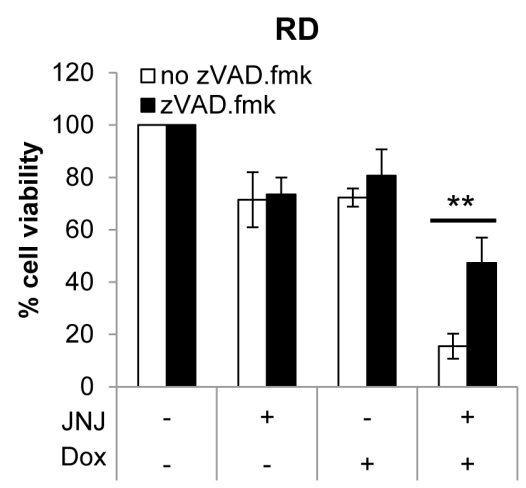

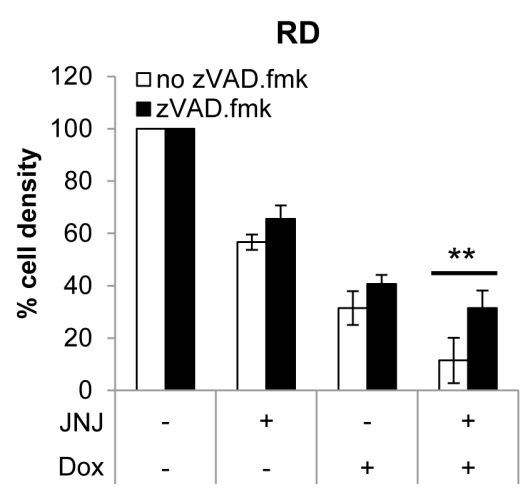

Figure 3: JNJ-26481585 and Doxorubicin cooperate to induce caspase activation and caspase-dependent apoptosis. A., Cells were treated with $15 \mathrm{nM} \mathrm{JNJ}-26481585$ and $/$ or $0.25 \mu \mathrm{g} / \mathrm{ml}$ Doxorubicin for indicated times. Cleavage of caspase- $9,-8,-3$ and PARP was assessed by Western blotting, GAPDH served as loading control. B., Cells were treated for indicated times with $15 \mathrm{nM} \mathrm{JNJ-26481585}$ and/or $0.25 \mu \mathrm{g} / \mathrm{ml}$ Doxorubicin. Apoptosis was determined by analysis of DNA fragmentation of PI-stained nuclei using flow cytometry. Mean and SEM of at least three independent experiments carried out in triplicate are shown; $* * P<0.01$. C., Cells were treated for 48 hours with $15 \mathrm{nM} \mathrm{JNJ}-26481585 \mathrm{and} /$ or $0.25 \mu \mathrm{g} / \mathrm{ml}$ Doxorubicin in the presence and absence of $50 \mu \mathrm{M} \mathrm{zVAD}$.fmk. Apoptosis was determined by analysis of DNA fragmentation of PI-stained nuclei using flow cytometry. Mean and SEM of at least three independent experiments carried out in triplicate are shown; $* P<0.05, * * P<0.01$. D., Cells were treated for 48 hours with $15 \mathrm{nM} \mathrm{JNJ}-26481585 \mathrm{and} /$ or $0.25 \mu \mathrm{g} / \mathrm{ml}$ Doxorubicin in the presence and absence of $50 \mu \mathrm{M}$ zVAD.fmk. Cell viability was measured by MTT assay. Mean and SEM of at least three independent experiments carried out in triplicate are shown; $* * P<0.01$. E., Cells were treated for 48 hours with $15 \mathrm{nM} \mathrm{JNJ}-26481585$ and/ or $0.25 \mu \mathrm{g} / \mathrm{ml}$ Doxorubicin in the presence and absence of $50 \mu \mathrm{M}$ zVAD.fmk. Cell density was measured by crystal violet assay. Mean and SEM of at least three independent experiments carried out in triplicate are shown; $* * P<0.01$.

\section{JNJ-26481585/Doxorubicin cotreatment shifts the balance of pro- and antiapoptotic proteins}

Next, we investigated the effect of JNJ-26481585 and Doxorubicin on expression levels of pro- and antiapoptotic proteins of the Bcl-2 family, which are known as key regulators of apoptosis. Treatment with JNJ-26481585- or JNJ-26481585/ Doxorubicin resulted in upregulation of $\mathrm{Bim}_{\mathrm{EL}}$ and of $\mathrm{Bmf}$ in Rh30 cells (Figure 4A). In addition, Noxa expression increased at early time points upon cotreatment with JNJ-26481585 and Doxorubicin (Figure 4B). Also, JNJ-26481585 and Doxorubicin cooperated to reduce protein levels of Mcl-1 and Bcl- $\mathrm{x}_{\mathrm{L}}$ (Figure 4A). These findings were confirmed in another RMS cell line (Suppl. Figure 4) and point to a shift in the ratio of pro- and antiapoptotic $\mathrm{Bcl}-2$ proteins upon JNJ-264815/Doxorubicin cotreatment.

To investigate the relevance of Bim and Noxa in JNJ-26481585/Doxorubicin-mediated cell death, we genetically silenced each gene using two distinct siRNA oligonucleotides. Importantly, individual silencing of Bim or Noxa, which was demonstrated by Western blot analysis (Figure 4C and 4D, upper panels), significantly impeded JNJ-26481585/Doxorubicin-induced cell death (Figure 4C and 4D, lower panels). Together, these results demonstrate that the $\mathrm{BH} 3$-only proteins Bim and Noxa are necessary for JNJ-26481585-induced cell death. 


\section{JNJ-26481585/Doxorubicin}

cotreatment stimulates activation of Bax and Bak, which are required for apoptosis

Since we observed that expression levels of Bax and Bak remained largely unchanged upon treatment with JNJ-26481585 and Doxorubicin in both cell lines (Figure $4 \mathrm{~A}$ ), we asked the question whether JNJ-26481585/ Doxorubicin cotreatment instead stimulates activation of Bax and Bak, two multidomain proapoptotic Bcl-
2 proteins that play an important role in the control of MOMP. To address this question we immunoprecipitated Bax and Bak by conformation-specific antibodies, since a conformational change marks their activation status [20, 21]. Of note, JNJ-26481585 and Doxorubicin cooperated to stimulate activation of Bax and/or Bak (Figure 5A, lanes $6,8,14$ and 16).

To investigate the functional relevance of Bax/ Bak activation for JNJ-26481585/Doxorubicin-mediated apoptosis we genetically silenced each gene using two distinct siRNA oligonucleotides (Figure 5B and 5C, upper

A

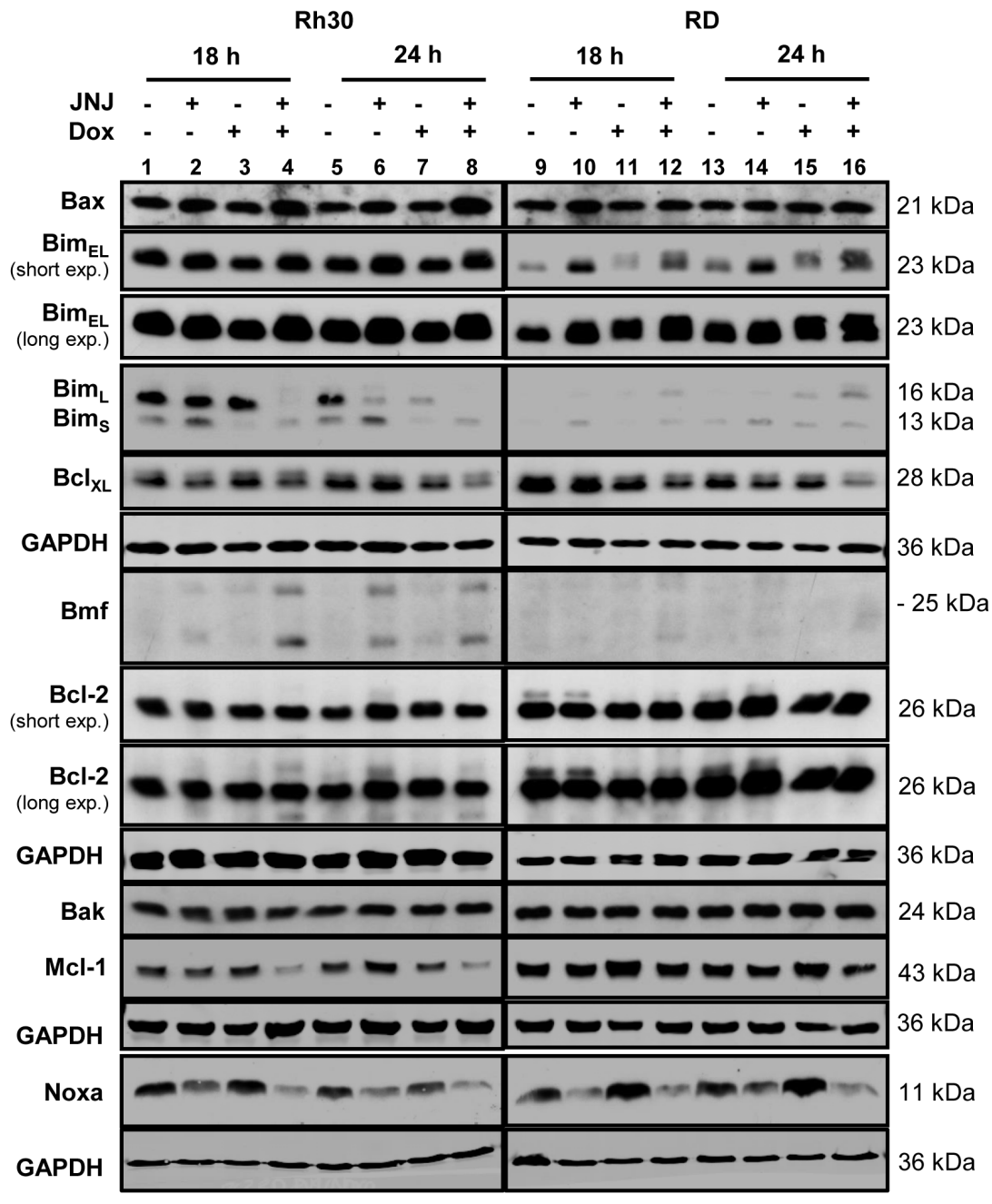

B

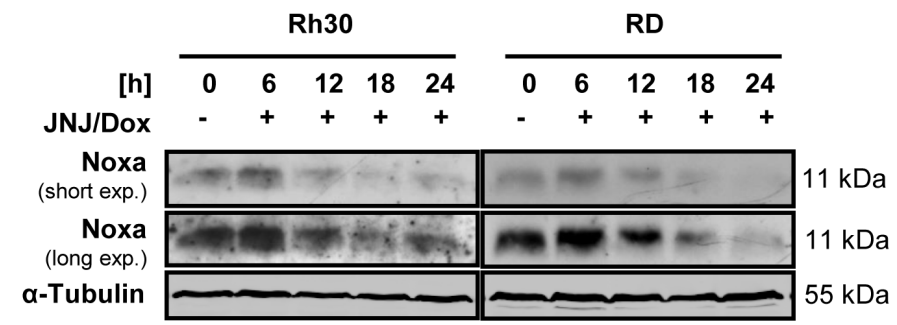




\section{C}
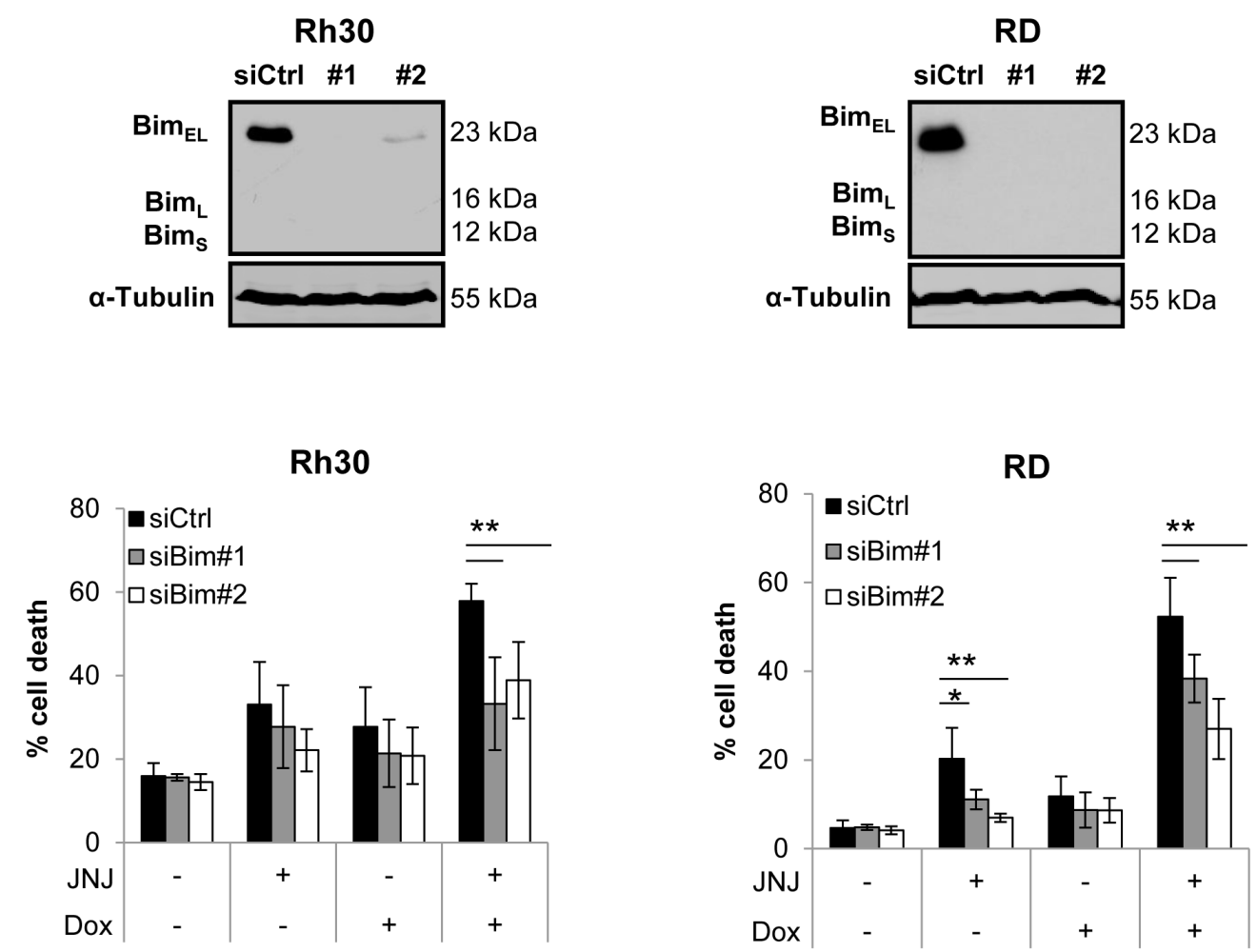

D
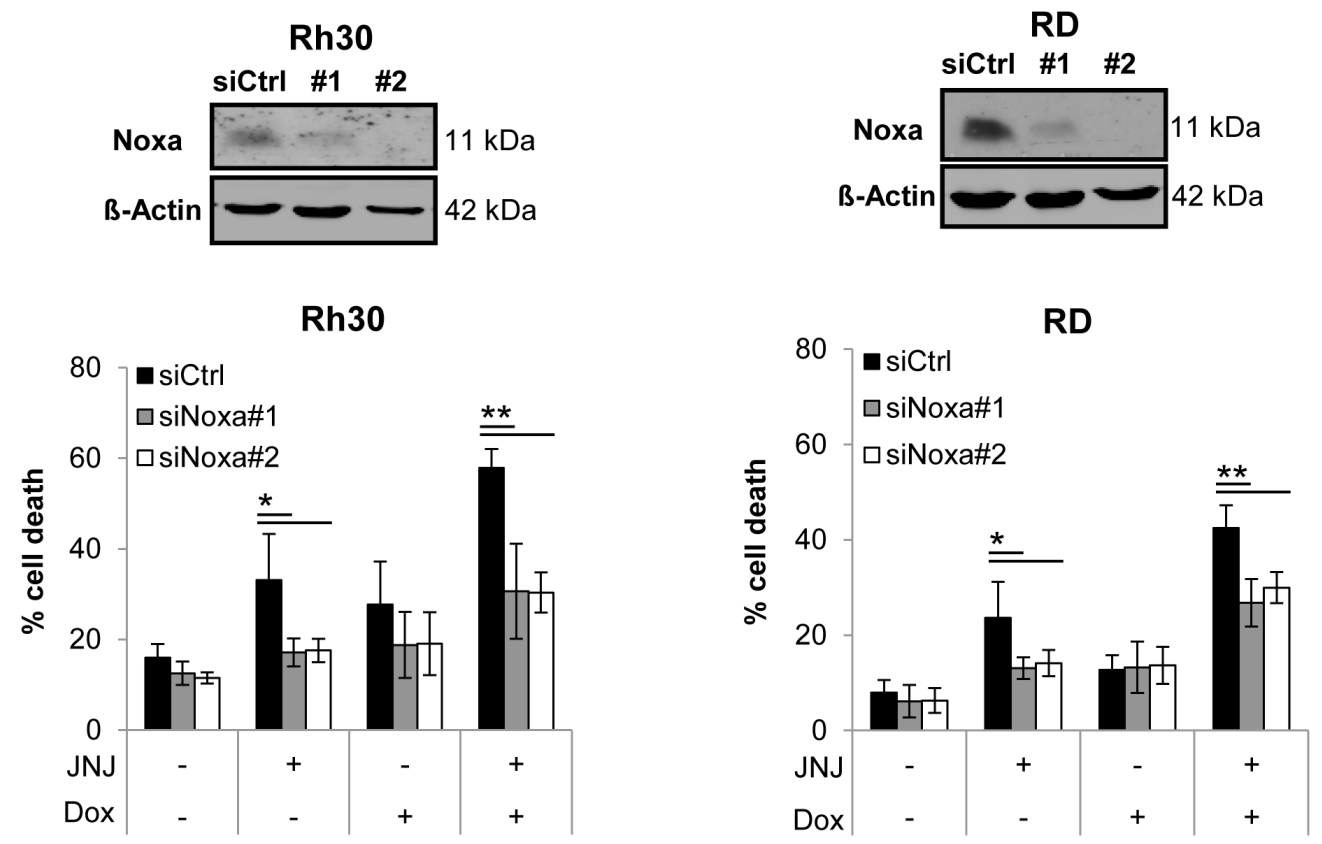

Figure 4: JNJ-26481585/Doxorubicin cotreatment shifts the balance of pro- and antiapoptotic proteins. A., Cells were treated with $15 \mathrm{nM} \mathrm{JNJ}-26481585 \mathrm{and} / \mathrm{or} 0.25 \mu \mathrm{g} / \mathrm{ml}$ Doxorubicin for indicated times. Protein expression of pro- and antiapoptotic Bcl-2 proteins was assessed by Western blotting, GAPDH served as loading control. B., Cells were treated with $15 \mathrm{nM} \mathrm{JNJ}-26481585$ and/or 0.25 $\mu \mathrm{g} / \mathrm{ml}$ Doxorubicin for indicated times. Protein expression of Noxa was assessed by Western blotting, $\alpha$-Tubulin served as loading control. C. and D., RMS cells were transiently transfected with siRNA against Bim, Noxa or non-targeting control siRNA. Expression of Bim and Noxa were assessed by Western blotting, GAPDH or B-Actin served as loading controls (upper panels). Transfected cells were treated with $15 \mathrm{nM} \mathrm{JNJ}-26481585 \mathrm{and} /$ or $0.25 \mu \mathrm{g} / \mathrm{ml}$ Doxorubicin for 30 hours and apoptosis was determined by analysis of DNA fragmentation of PI- or SYTOX ${ }^{\circledR}$ Blue-stained nuclei using flow cytometry (lower panels). Mean and SEM of three independent experiments carried out in triplicate are shown; ${ }^{*} P<0.05 ; * * P<0.01$. 
panels). Remarkably, knockdown of either Bax or Bak significantly reduced JNJ-26481585/Doxorubicin-induced apoptosis (Figure 5B and 5C, lower panels). This shows that Bax/Bak activation is required for JNJ-26481585/ Doxorubicin-induced cell death.

\section{Overexpression of Bcl-2 inhibits JNJ-26481585/ Doxorubicin-induced apoptosis}

To further explore whether activation of the mitochondrial apoptotic pathway represents a critical event during JNJ-26481585/Doxorubicin-induced apoptosis, we overexpressed the antiapoptotic protein $\mathrm{Bcl}-2$, which has been reported to impair mitochondria-mediated apoptotic signaling events [9]. Ectopic expression of murine Bcl2 was confirmed using an antibody that specifically detects the ectopically expressed murine Bcl-2 (Figure 6A). Importantly, overexpression of Bcl-2 significantly reduced JNJ-26481585/Doxorubicin-induced DNA fragmentation as well as loss of cell viability (Figure $6 \mathrm{~B}$ and $6 \mathrm{C}$ ). Also, Bcl-2 overexpression abolished JNJ26481585/Doxorubicin-stimulated activation of Bax and Bak (Suppl. Figure 5). These results emphasize the notion that JNJ-26481585/Doxorubicin-induced apoptosis depends on intact signaling via the mitochondrial pathway of apoptosis.

A
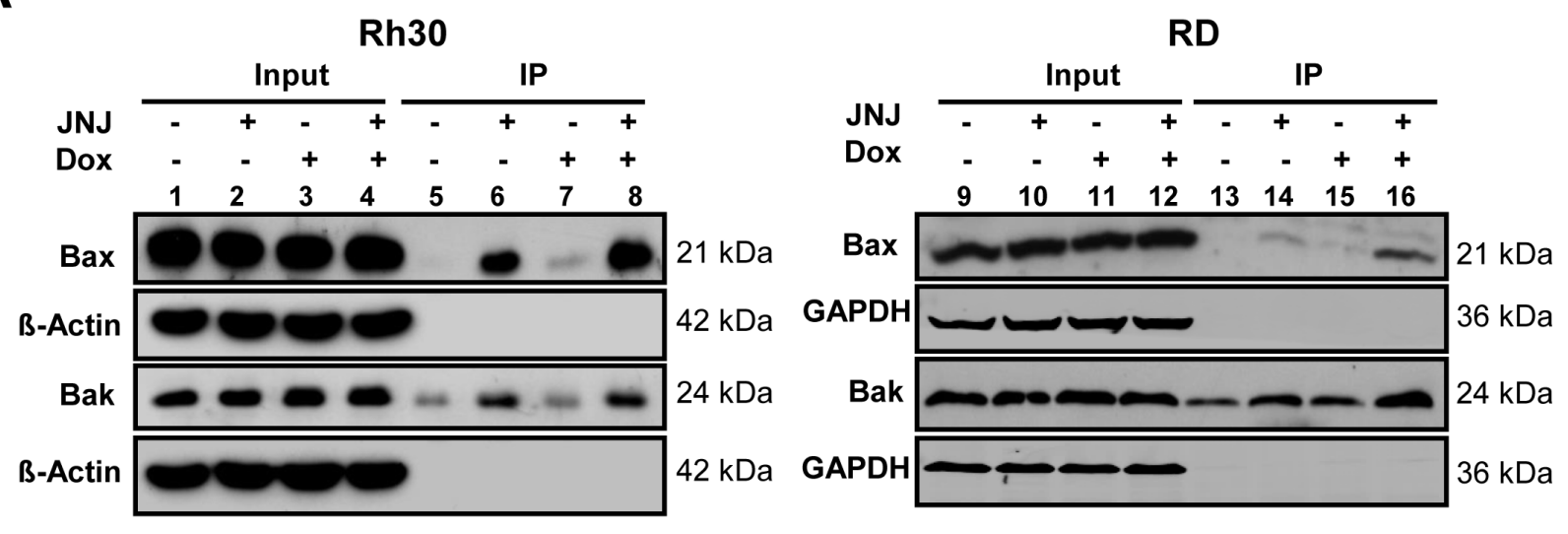

B

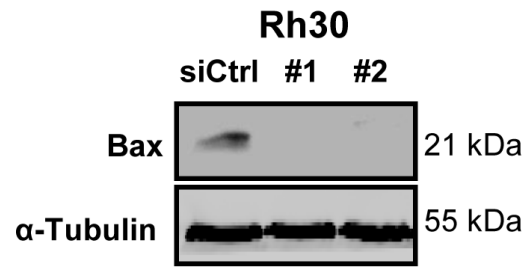

Rh30

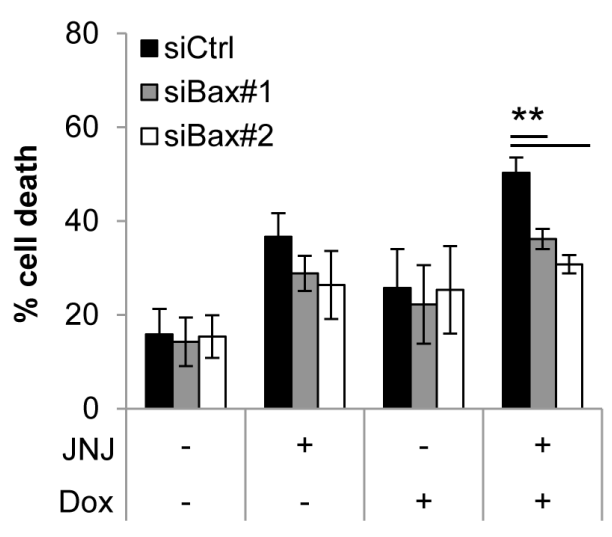

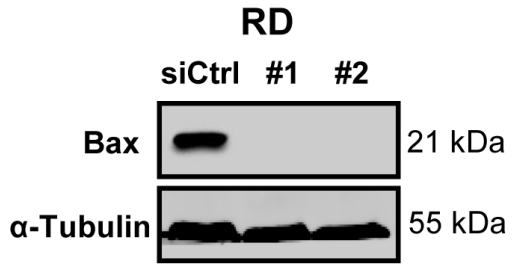

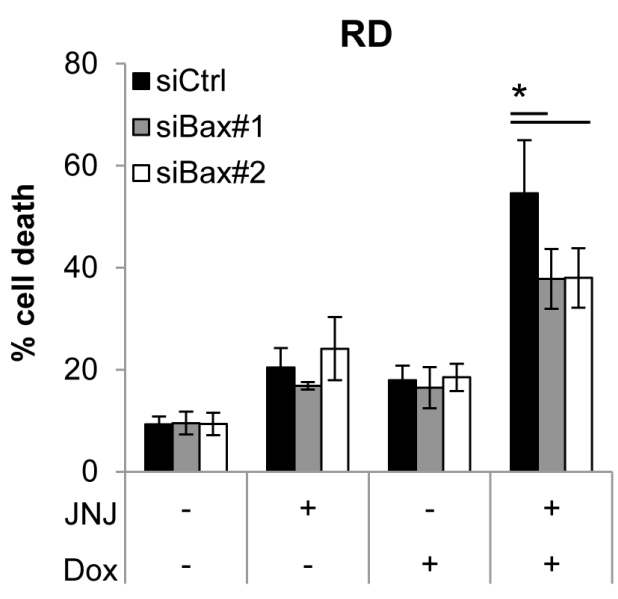




\section{C}

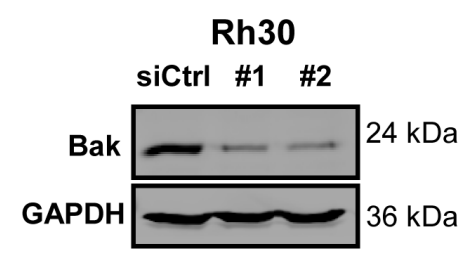

Rh30

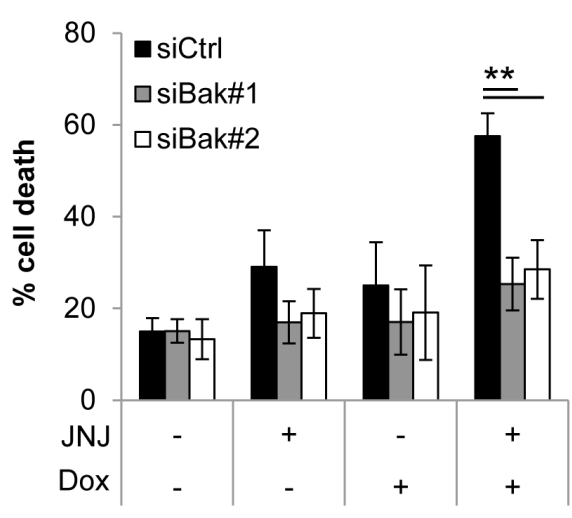

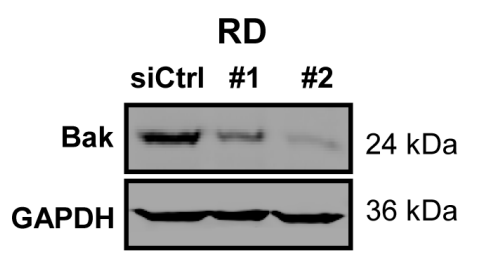

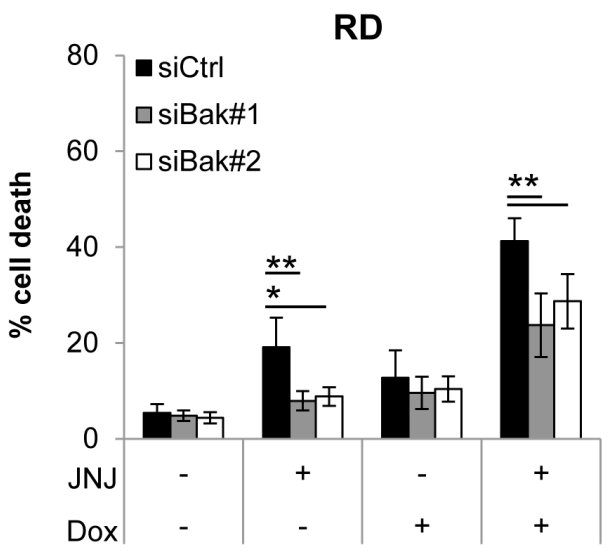

Figure 5: JNJ-26481585/Doxorubicin cotreatment stimulates activation of Bax and Bak, which are required for apoptosis. A., Cells were treated for 18 hours with $15 \mathrm{nM} \mathrm{JNJ}-26481585 \mathrm{and} / \mathrm{or} 0.25 \mu \mathrm{g} / \mathrm{ml}$ Doxorubicin. Activation of Bax and Bak was assessed by immunoprecipitation using active conformation-specific anti-Bax or anti-Bak antibodies and protein expression of Bax, Bak GAPDH and $\beta$-Actin was analyzed by Western blotting. B. and C., RMS cells were transiently transfected with siRNA against Bak, Bax or non-targeting control siRNA. Expression of Bak and Bax was assessed by Western blotting, GAPDH or $\alpha$-Tubulin served as loading controls (upper panels). Transfected cells were treated with $15 \mathrm{nM} \mathrm{JNJ}-26481585 \mathrm{and} / \mathrm{or} 0.25 \mu \mathrm{g} / \mathrm{ml}$ Doxorubicin for 30 hours and apoptosis was determined by analysis of DNA fragmentation of PI- or SYTOX ${ }^{\circledR}$ Blue-stained nuclei using flow cytometry (lower panels). Mean and SEM of three independent experiments carried out in triplicate are shown; $* P<0.05 ; * * P<0.01$.

\section{DISCUSSION}

In recent years, there has been a growing interest in using HDACIs for the treatment of cancers including pediatric malignancies such as RMS. Of note, HDACIs as a class turned out to be active against RMS cells in a recent screen of a custom library of about 200 compounds including chemotherapeutics, Food and Drug Administration-approved drugs and small molecules with biological activity [22]. Furthermore, Vorinostat is currently being evaluated in early clinical trials for the treatment of childhood cancers including RMS [23]. The second-generation HDACI JNJ-26481585 has been documented to exhibit improved pharmacodynamic properties over other HDAC inhibitory compounds, demonstrating sustained histone acetylation in tissues and tumors [11]. Against this background, we investigated the question whether JNJ-26481585 could be employed to enhance the sensitivity of RMS cells towards chemotherapeutics.

In this study, we identify the synergistic interaction of JNJ-26481585 together with chemotherapeutic agents to trigger apoptosis in RMS cells. JNJ-26481585 sensitizes
RMS cells for apoptosis induced by several anticancer drugs, which are commonly used in the clinic for the treatment of RMS, including Doxorubicin, Etoposide, Vincristine, Cyclophosphamide and Actinomycin D [15], thus underscoring the clinical relevance of this chemosensitization. In contrast to RMS cells, JNJ26481585 does not enhance the cytotoxicity of anticancer drugs such as Doxorubicin or Etoposide against nonmalignant fibroblasts, pointing to some tumor selectivity. Importantly, the combination of JNJ-26481585 and Doxorubicin significantly suppresses tumor growth in a preclinical in vivo model of RMS and inhibits longterm clonogenic growth of RMS cells. While we used co-treatment with JNJ-26481585 and Doxorubicin to identify synergistic drug interactions, it remains subject to further studies to explore the effects of different treatment schedules on synergism.

Mechanistic studies revealed that the synergism of JNJ-26481585 and Doxorubicin involves cooperative induction of apoptosis via the mitochondrial pathway, as demonstrated by several lines of evidence. First, activation of the mitochondrial apoptotic pathway is demonstrated by the following typical parameters. JNJ-26481585 


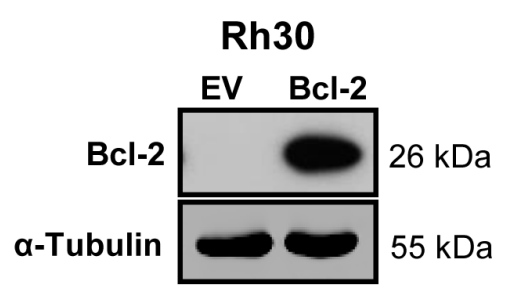

B

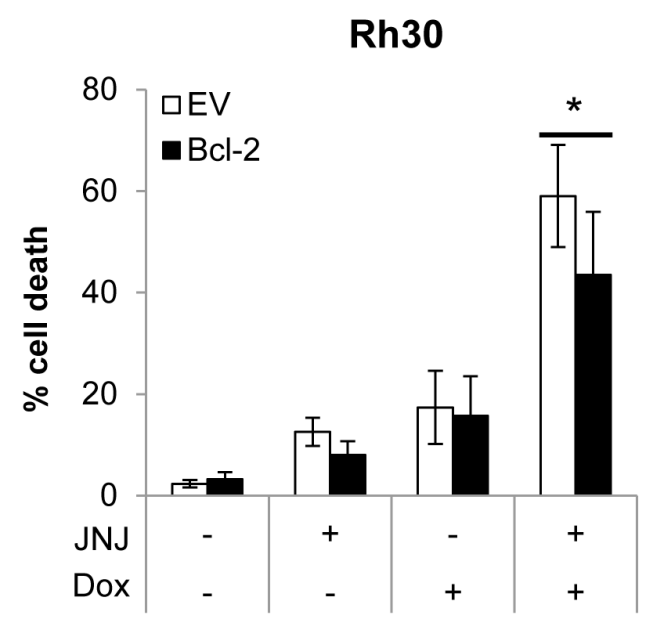

C

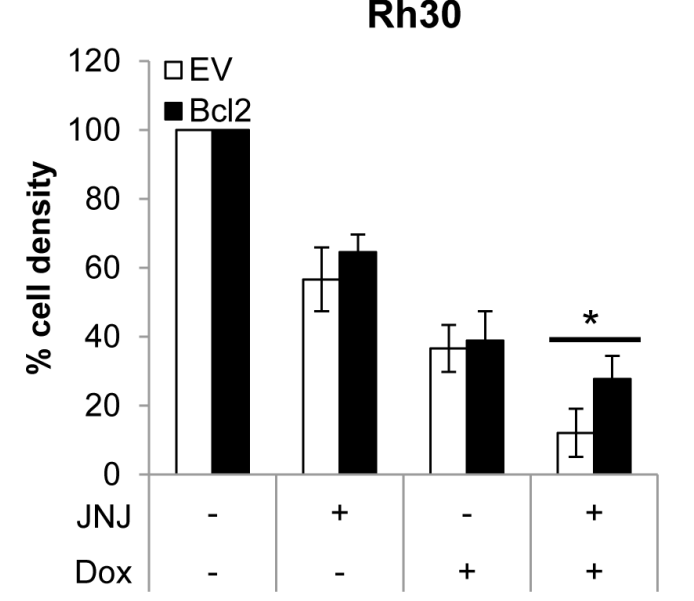

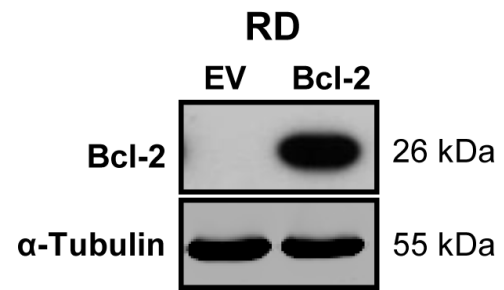

RD

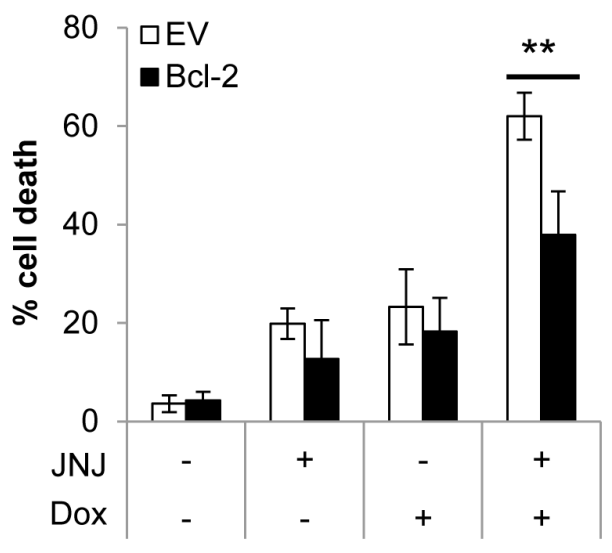

Figure 6: Overexpression of Bcl-2 inhibits JNJ-26481585/Doxorubicin-induced apoptosis. A., Cells were transfected with murine Bcl-2 or empty vector (EV) and expression of Bcl-2 was assessed by Western blotting, $\alpha$-Tubulin served as loading control. B., Cells were treated with $15 \mathrm{nM} \mathrm{JNJ}-26481585$ and/or $0.25 \mu \mathrm{g} / \mathrm{ml}$ Doxorubicin for 48 hours. Apoptosis was determined by analysis of DNA fragmentation of PI-stained nuclei using flow cytometry. Mean and SEM of three independent experiments carried out in triplicate are shown; ${ }^{*} P<0.05 ; * * P<0.01$. C., Cells were treated with $15 \mathrm{nM} \mathrm{JNJ}-26481585 \mathrm{and} / \mathrm{or} 0.25 \mu \mathrm{g} / \mathrm{ml}$ Doxorubicin for 48 hours. Cell density was measured by crystal violet assay. Mean and SEM of at least three independent experiments carried out in triplicate are shown; $* P<$ $0.05, * * P<0.01$. 
and Doxorubicin act in concert to shift the ratio of proand antiapoptotic Bcl-2 proteins in favor of apoptosis, thereby facilitating the activation of the mitochondrial gatekeeper proteins Bax and Bak, which in turn leads to activation of caspases and DNA fragmentation. Caspasedependent apoptosis was confirmed by experiments using the broad-range caspase inhibitor zVAD.fmk, which significantly rescues JNJ-26481585/Doxorubicin-induced apoptosis. Second, rescue experiments demonstrate that the $\mathrm{BH} 3$-only domain proteins Bim and Noxa as well as the multidomain proteins Bax and Bak are required for apoptosis, since individual silencing of Bim, Noxa, Bax or Bak significantly impedes JNJ-26481585/Doxorubicininduced apoptosis. Third, JNJ-26481585/Doxorubicin cotreatment causes downregulation of the antiapoptotic proteins $\mathrm{Mcl}-1$ and $\mathrm{Bcl}-\mathrm{x}_{\mathrm{L}}$, which is in line with previous reports showing that HDACIs can also downregulate gene expression levels [8]. Fourth, ectopic expression of $\mathrm{Bcl}-2$, which is known to impede mitochondria-mediated apoptotic signaling events, significantly rescues JNJ26481585/Doxorubicin-induced apoptosis. Together, these mechanistic studies emphasize the critical role of the mitochondrial apoptosis pathway for JNJ-26481585/ Doxorubicin-induced apoptosis. In line with this notion, JNJ-26481585 has previously been described to act by downregulation of Mcl-1 and upregulation of Bid and Bim cells in multiple myeloma cells [24].

It has been shown before that HDACIs predominantly act by inducing apoptosis, either by the extrinsic or the intrinsic apoptotic pathway depending on the context [8]. We recently reported that Vorinostat, a firstgeneration HDACI, is able to sensitize RMS and Ewing sarcoma towards classical chemotherapeutics, especially Doxorubicin and Etoposide [25, 26]. However, nothing is known so far on rational combination therapies using the second-generation HDACI JNJ-26481585 in RMS. JNJ-26481585 represents a promising compound to target HDACs in pediatric cancers, since it has been reported to retard tumor growth in the majority of solid pediatric xenografts studied [14], whereas Vorinostat induced no objective responses among 30 evaluable solid childhood tumor xenografts [27]. Our study demonstrates for the very first time that JNJ-26481585 primes RMS cells for anticancer drug-triggered apoptosis. Since chemotherapy represents a central element of current treatment protocols for RMS [15], this synergistic interaction is of special interest for future clinical translation. Thus, this study provides an important rationale to transfer combinations of JNJ-26481585 together with anticancer drugs into clinical application for the treatment of RMS.

\section{MATERIALS AND METHODS}

\section{Cell culture and chemicals}

RMS cell lines were obtained from the American Type Culture Collection (Manassas, VA, USA) and maintained in RPMI 1640 or DMEM medium (Life Technologies, Inc., Darmstadt, Germany), supplemented with $10 \%$ fetal calf serum (FCS) (Biochrom, Berlin, Germany), 1\% penicillin/streptomycin and $1 \mathrm{mM}$ Sodium Pyruvate (Invitrogen, Karlsruhe, Germany). zVAD.fmk was purchased from Bachem (Heidelberg, Germany), 5-((7-Cl-1H-indol-3-yl)methyl)-3-methylimidazolidine2,4-dione) (7-Cl-O-Nec-1, Nec-1s) from Merck (Darmstadt, Germany), JNJ-26481585 from Selleck Chemicals (Houston, TX, USA), and all other chemicals from Sigma (Deisenhofen, Germany) unless indicated otherwise.

\section{Determination of cell viability, apoptosis and clonogenic growth}

For determination of cell viability and apoptosis cells were seeded at $0.3 \times 105$ cells $/ \mathrm{cm}^{2}$. Cell viability was determined by MTT assay according to the manufacturer's instructions (Roche Diagnostics, Mannheim, Germany) or by crystal violet assay by staining viable cells with crystal violet solution $(0.5 \%$ crystal violet, $30 \%$ ethanol, and $3 \%$ formaldehyde). Apoptosis was determined by flow cytometric analysis (FACSCanto II, BD Biosciences, Heidelberg, Germany) of DNA fragmentation of propidium iodide (PI)-stained nuclei as described previously [28]. Briefly, cells were seeded in a 24well plate, allowed to settle overnight and treated with indicated drug concentrations. After indicated treatment times, cells were washed with ice-cold PBS, resuspended in a buffer containing $0.05 \%$ trisodium citrate dihydrate $\mathrm{pH} 7.4,0.05 \%$ Triton X-100, $50 \mu \mathrm{g} / \mathrm{ml} \mathrm{PI})$, incubated at $4^{\circ} \mathrm{C}$ and apoptosis was determined by flow cytometry. In addition, apoptosis was assessed by SYTOX ${ }^{\circledR}$ Bluestained nuclei according to the manufacturer's instructions (Life Technologies, Inc.). To determine colony formation, 200 cells were seeded in a 6-well tissue culture plate, allowed to settle overnight and treated with $7.5 \mathrm{nM}$ JNJ26481585 for 23 hours before $0.015 \mu \mathrm{g} / \mathrm{ml}$ Doxorubicin was added for 1 hour. Then, medium was exchanged and colonies were stained after 12 days with crystal violet solution. To analyze cooperative drug interaction, drug concentrations and treatment duration were modified for colony formation assay due to the prolonged assay period and the reduced initial cell density. Colonies containing more than 50 cells were counted and the percentage of surviving colonies relative to solvent-treated controls was calculated. 


\section{Transduction}

For Bcl-2 overexpression, Phoenix packaging cells were transfected with $20 \mu \mathrm{g}$ of murine stem-cell virus (pMSCV, Clontech, Mountain View CA) vector containing murine Bcl-2 or empty vector using calcium phosphate transfection as described previously [25]. Stable cell lines were generated by lentiviral transduction and were selected with $10 \mu \mathrm{g} / \mathrm{ml}$ Blasticidin (Invitrogen).

\section{RNA interference}

For transient knockdown by siRNA, cells were reversely transfected with 10-20 nM SilencerSelect siRNA (Life Technologies, Inc.), i.e. control siRNA (4390843) or targeting siRNAs (s1880 and s1881 for Bak, s1888 and s1890 for Bax, s195011 and s223065 for Bim, s10708 and s10709 for Noxa) using Lipofectamine RNAi Max reagent and OptiMEM (Life Technologies, Inc.).

\section{Western blot analysis}

Western blot analysis was performed as described previously [28] using the following antibodies: mouse anti-caspase-8, mouse anti-Noxa, rat anti-Bmf (Alexis Biochemicals, Grünberg, Germany), mouse anti-Bcl-2, rabbit anti-Bcl- $\mathrm{x}_{\mathrm{L}}$, mouse anti-Bax, rabbit anti-Bak (BD Transduction Laboratories, Heidelberg, Germany), rabbit anti-caspase-3, rabbit anti-caspase-9, rabbit antiBim, mouse anti-PARP (Cell Signaling, Beverly, MA), acetylated histone H3 (Upstate Biotechnology, Lake Placid, NY), rabbit anti-Mcl-1 (Stressgene, Victoria, $\mathrm{BC}$ ), rabbit histone $\mathrm{H} 3$ (Abcam, Cambridge, UK). Mouse anti-GAPDH (HyTest, Turku, Finland), mouse $\alpha$-Tubulin (Calbiochem, Darmstadt, Germany) or mouse $\beta$-Actin (Sigma) were used as loading controls. Goat anti-mouse $\mathrm{IgG}$, goat anti-rabbit $\operatorname{IgG}$ conjugated to horseradish peroxidase (Santa Cruz Biotechnology, Santa Cruz, CA) were used as secondary antibodies. Enhanced chemiluminescence (Amersham Bioscience, Freiburg, Germany) or infrared dye-labeled secondary antibodies and infrared imaging (Odyssey Imaging System, LICOR Bioscience, Bad Homburg, Germany) were used for detection. Representative blots of at least two independent experiments are shown.

\section{Determination of activation of Bax and Bak}

For detection of active Bax or Bak, cells were lysed in CHAPS lysis buffer (10 mM HEPES (pH 7.4); 150 $\mathrm{mM} \mathrm{NaCl} ; 1 \%$ CHAPS) as previously described [29]. Briefly, 700-1000 $\mu \mathrm{g}$ protein was immunoprecipitated and incubated overnight at $4{ }^{\circ} \mathrm{C}$ with $2 \mu \mathrm{g} / \mathrm{ml}$ mouse antiBax antibody (6A7, Sigma) or anti-Bak antibody (Ab-1;
Calbiochem) and $10 \mu 1$ pan-mouse IgG Dynabeads (Dako, Hamburg, Germany) and washed with CHAPS buffer. The precipitate was analyzed for Bax and Bak expression by Western blotting using the Bax NT antibody (Merck) or Bak antibody (BD Biosciences).

\section{CAM assay}

CAM assay was done as described previously [29]. Briefly, 1 x 106 cells were implanted on the CAM of fertilized chicken eggs on day 8 of incubation. The next three days, cells were treated with $15 \mathrm{nM} \mathrm{JNJ}-26481585$ and $0.25 \mu \mathrm{g} / \mathrm{ml}$ Doxorubicin. Four days after inoculation, tumors were excised with the surrounding CAM, fixed in $4 \%$ paraformaldehyde, embedded in paraffin, cut in $3 \mu \mathrm{m}$ sections and stained with 1:1 hematoxylin and $0.5 \%$ eosin solution for histological analysis. Images were digitally recorded with an AX70 microscope (Olympus, Center Valley, PA, USA) and tumor area was analyzed by Image J digital imaging software (NIH, Bethesda, MA, USA).

\section{Statistical analysis}

Statistical significance was assessed by Student's t-Test (two-tailed distribution, two-sample, unequal variance). Drug interaction was analyzed by the CI method using CalcuSyn software (Biosoft, Cambridge, UK). CI $<0.9$ indicates synergism, 0.9-1.1 additivity and $>1.1$ antagonism.

\section{ACKNOWLEDGMENTS} assistance.

We thank C. Hugenberg for expert secretarial

\section{CONFLICTS OF INTEREST}

None to declare.

\section{GRANT SUPPORT}

This work has been partially supported by grants from the BMBF and the Deutsche Kinderkrebsstiftung (to S. F.).

\section{REFERENCES}

1. Dagher R and Helman L. Rhabdomyosarcoma: an overview. Oncologist. 1999; 4: 34-44.

2. Hayes-Jordan A and Andrassy R. Rhabdomyosarcoma in children. Curr Opin Pediatr. 2009; 21: 373-378.

3. Dantonello TM, Int-Veen C, Harms D, Leuschner I, Schmidt BF, Herbst M, Juergens H, Scheel-Walter HG, Bielack SS, Klingebiel T, Dickerhoff R, Kirsch S, Brecht 
I, et al. Cooperative trial CWS-91 for localized soft tissue sarcoma in children, adolescents, and young adults. J Clin Oncol. 2009; 27: 1446-1455.

4. Ellis L, Atadja PW and Johnstone RW. Epigenetics in cancer: targeting chromatin modifications. Mol Cancer Ther. 2009; 8: 1409-1420.

5. Cress WD and Seto E. Histone deacetylases, transcriptional control, and cancer. J Cell Physiol. 2000; 184: 1-16.

6. Timmermann S, Lehrmann H, Polesskaya A and HarelBellan A. Histone acetylation and disease. Cell Mol Life Sci. 2001; 58: 728-736.

7. Bolden JE, Peart MJ and Johnstone RW. Anticancer activities of histone deacetylase inhibitors. Nat Rev Drug Discov. 2006; 5: 769-784.

8. Matthews GM, Newbold A and Johnstone RW. Intrinsic and extrinsic apoptotic pathway signaling as determinants of histone deacetylase inhibitor antitumor activity. Adv Cancer Res. 2012; 116: 165-197.

9. Fulda S, Galluzzi L and Kroemer G. Targeting mitochondria for cancer therapy. Nat Rev Drug Discov. 2010; 9: 447-464.

10. Adams JM and Cory S. The Bcl-2 apoptotic switch in cancer development and therapy. Oncogene. 2007; 26: 1324-1337.

11. Arts J, King P, Marien A, Floren W, Belien A, Janssen L, Pilatte I, Roux B, Decrane L, Gilissen R, Hickson I, Vreys $\mathrm{V}$, Cox E, et al. JNJ-26481585, a novel "second-generation" oral histone deacetylase inhibitor, shows broad-spectrum preclinical antitumoral activity. Clin Cancer Res. 2009; 15: 6841-6851.

12. Venugopal B, Baird R, Kristeleit RS, Plummer R, Cowan R, Stewart A, Fourneau N, Hellemans P, Elsayed Y, McClue S, Smit JW, Forslund A, Phelps C, et al. A phase I study of quisinostat (JNJ-26481585), an oral hydroxamate histone deacetylase inhibitor with evidence of target modulation and antitumor activity, in patients with advanced solid tumors. Clin Cancer Res. 2013; 19: 4262-4272.

13. Deleu S, Lemaire M, Arts J, Menu E, Van Valckenborgh E, King P, Vande Broek I, De Raeve H, Van Camp B, Croucher $\mathrm{P}$ and Vanderkerken $\mathrm{K}$. The effects of JNJ26481585, a novel hydroxamate-based histone deacetylase inhibitor, on the development of multiple myeloma in the 5T2MM and 5T33MM murine models. Leukemia. 2009; 23: 1894-1903.

14. Carol H, Gorlick R, Kolb EA, Morton CL, Manesh DM, Keir ST, Reynolds CP, Kang MH, Maris JM, Wozniak A, Hickson I, Lyalin D, Kurmasheva RT, et al. Initial testing (stage 1) of the histone deacetylase inhibitor, quisinostat (JNJ-26481585), by the Pediatric Preclinical Testing Program. Pediatr Blood Cancer. 2014; 61: 245-252.

15. Weiss A, Gill J, Goldberg J, Lagmay J, Spraker-Perlman $\mathrm{H}$, Venkatramani R and Reed D. Advances in therapy for pediatric sarcomas. Curr Oncol Rep. 2014; 16: 395.

16. Vogler M, Walczak H, Stadel D, Haas TL, Genze F, Jovanovic M, Bhanot U, Hasel C, Moller P, Gschwend JE,
Simmet T, Debatin KM and Fulda S. Small molecule XIAP inhibitors enhance TRAIL-induced apoptosis and antitumor activity in preclinical models of pancreatic carcinoma. Cancer Res. 2009; 69: 2425-2434.

17. Stupack DG, Teitz T, Potter MD, Mikolon D, Houghton PJ, Kidd VJ, Lahti JM and Cheresh DA. Potentiation of neuroblastoma metastasis by loss of caspase-8. Nature. 2006; 439: 95-99.

18. Graab U, Hahn H and Fulda S. Identification of a novel synthetic lethality of combined inhibition of hedgehog and PI3K signaling in rhabdomyosarcoma. Oncotarget. 2015; 6: 8722-8735.

19. Hugle M, Belz K and Fulda S. Identification of synthetic lethality of PLK1 inhibition and microtubule-destabilizing drugs. Cell Death Differ. 2015; May 29 [E-pub ahead of print].

20. Desagher S, Osen-Sand A, Nichols A, Eskes R, Montessuit S, Lauper S, Maundrell K, Antonsson B and Martinou JC. Bid-induced conformational change of Bax is responsible for mitochondrial cytochrome $\mathrm{c}$ release during apoptosis. J Cell Biol. 1999; 144: 891-901.

21. Griffiths GJ, Dubrez L, Morgan CP, Jones NA, Whitehouse J, Corfe BM, Dive C and Hickman JA. Cell damageinduced conformational changes of the pro-apoptotic protein Bak in vivo precede the onset of apoptosis. J Cell Biol. 1999; 144: 903-914.

22. Chen X, Stewart E, Shelat AA, Qu C, Bahrami A, Hatley M, Wu G, Bradley C, McEvoy J, Pappo A, Spunt S, Valentine MB, Valentine V, et al. Targeting oxidative stress in embryonal rhabdomyosarcoma. Cancer Cell. 2013; 24: 710-724.

23. Witt O, Milde T, Deubzer HE, Oehme I, Witt R, Kulozik A, Eisenmenger A, Abel U and Karapanagiotou-Schenkel I. Phase I/II intra-patient dose escalation study of vorinostat in children with relapsed solid tumor, lymphoma or leukemia. Klin Padiatr. 2012; 224: 398-403.

24. Stuhmer T, Arts J, Chatterjee M, Borawski J, Wolff A, King P, Einsele H, Leo E and Bargou RC. Preclinical anti-myeloma activity of the novel HDAC-inhibitor JNJ26481585. Br J Haematol. 2010; 149: 529-536.

25. Heinicke $U$ and Fulda S. Chemosensitization of rhabdomyosarcoma cells by the histone deacetylase inhibitor SAHA. Cancer Lett. 2014; 351: 50-58.

26. Unland R, Clemens D, Heinicke U, Potratz JC, Hotfilder M, Fulda S, Wardelmann E, Fruhwald MC and Dirksen U. Suberoylanilide hydroxamic acid synergistically enhances the antitumor activity of etoposide in Ewing sarcoma cell lines. Anticancer Drugs. 2015; 26: 843-851.

27. Keshelava N, Houghton PJ, Morton CL, Lock RB, Carol H, Keir ST, Maris JM, Reynolds CP, Gorlick R, Kolb EA, $\mathrm{Wu} \mathrm{J}$ and Smith MA. Initial testing (stage 1) of vorinostat (SAHA) by the pediatric preclinical testing program. Pediatr Blood Cancer. 2009; 53: 505-508.

28. Fulda S, Sieverts H, Friesen C, Herr I and Debatin KM. 
The CD95 (APO-1/Fas) system mediates drug-induced apoptosis in neuroblastoma cells. Cancer Res. 1997; 57: 3823-3829.

29. Hacker S, Dittrich A, Mohr A, Schweitzer T, Rutkowski S, Krauss J, Debatin KM and Fulda S. Histone deacetylase inhibitors cooperate with IFN-gamma to restore caspase-8 expression and overcome TRAIL resistance in cancers with silencing of caspase-8. Oncogene. 2009; 28: 3097-3110. 